\title{
A rare case of an ACTH/CRH co-secreting midgut neuroendocrine tumor mimicking Cushing's disease
}

\author{
Regina Streuli', Ina Krull', Michael Brändle', Walter Kolb2', Günter Stalla³, \\ Marily Theodoropoulou ${ }^{3}$, Annette Enzler-Tschudy ${ }^{4}$ and Stefan Bilz ${ }^{1}$
}

1Division of Endocrinology and Diabetes, Department of Internal Medicine, and 2Department of Surgery, Kantonsspital St Gallen, St Gallen, Switzerland, ${ }^{3}$ Clinical Neuroendocrinology, Max Planck Institute of

Psychiatry, Munich, Germany, and ${ }^{4}$ Institute of Pathology, Kantonsspital St Gallen, St Gallen, Switzerland

\author{
Correspondence \\ should be addressed \\ to S Bilz \\ Email \\ stefan.bilz@kssg.ch
}

\section{Summary}

Ectopic ACTH/CRH co-secreting tumors are a very rare cause of Cushing's syndrome and only a few cases have been reported in the literature. Differentiating between Cushing's disease and ectopic Cushing's syndrome may be particularly difficult if predominant ectopic CRH secretion leads to pituitary corticotroph hyperplasia that may mimic Cushing's disease during dynamic testing with both dexamethasone and CRH as well as bilateral inferior petrosal sinus sampling (BIPSS). We present the case of a 24-year-old man diagnosed with ACTH-dependent Cushing's syndrome caused by an ACTH/CRH co-secreting midgut NET. Both high-dose dexamethasone testing and BIPSS suggested Cushing's disease. However, the clinical presentation with a rather rapid onset of cushingoid features, hyperpigmentation and hypokalemia led to the consideration of ectopic ACTH/CRH-secretion and prompted a further workup. Computed tomography (CT) of the abdomen revealed a cecal mass which was identified as a predominantly $\mathrm{CRH}$-secreting neuroendocrine tumor. To the best of our knowledge, this is the first reported case of an ACTH/CRH co-secreting tumor of the cecum presenting with biochemical features suggestive of Cushing's disease.

\section{Learning points:}

- The discrimination between a Cushing's disease and ectopic Cushing's syndrome is challenging and has many caveats.

- Ectopic ACTH/CRH co-secreting tumors are very rare.

- Dynamic tests as well as BIPSS may be compatible with Cushing's disease in ectopic CRH-secretion.

- High levels of CRH may induce hyperplasia of the corticotroph cells in the pituitary. This could be the cause of a preserved pituitary response to dexamethasone and CRH.

- Clinical features of ACTH-dependent hypercortisolism with rapid development of Cushing's syndrome, hyperpigmentation, high circulating levels of cortisol with associated hypokalemia, peripheral edema and proximal myopathy should be a warning flag of ectopic Cushing's syndrome and lead to further investigations.

\section{Background}

Pituitary corticotroph adenomas (Cushing's disease) account for the vast majority of cases diagnosed with ACTH-dependent hypercortisolism and only 5-10\% result from ectopic sources of ACTH and very rarely CRH. Since up to $50 \%$ of corticotroph adenomas may not be visualized by pituitary MRI it is of utmost importance 
to rule out ectopic ACTH/CRH-secretion to prevent unnecessary pituitary exploratory surgery and employ the correct imaging procedures to identify the ACTH source. Ectopic CRH or ACTH/CRH co-secreting tumors are a very rare cause of Cushing's syndrome and only few cases have been reported in the literature $(1,2,3,4,5,6,7,8,9$, $10,11,12,13,14,15)$. Bronchial and thymic carcinoids, islet cell carcinomas, pheochromocytomas, medullary thyroid cancers, pancreatic tumors, gastrinomas, liver tumors and small-cell lung cancers have been identified as sources of ACTH/CRH co-secretion. Importantly, pituitary corticotroph hyperplasia secondary to tumor-derived CRH-stimulation may significantly impact dynamic tests employed during the workup of ACTH-dependent Cushing's syndrome. We report a case of an ACTH/CRH co-secreting neuroendocrine tumor of the cecum/ appendix mimicking Cushing's disease.
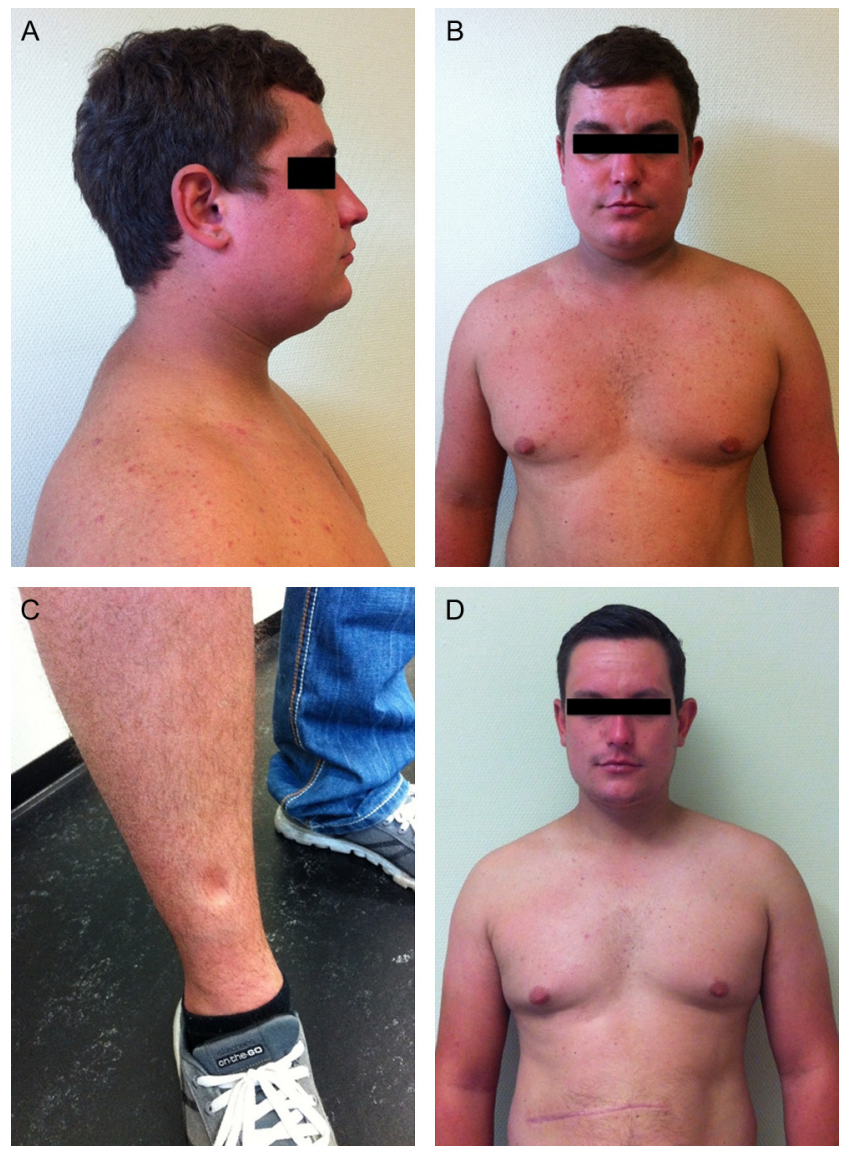

\section{Figure 1}

The patient shows severe signs of Cushing's syndrome. (A) Buffalo hump, hyperpigmentation, (B) acne, supraclaviculare fat pads and (C) pitting edema of the leg. (D) Signs from Cushing's syndrome resolved within a few months after resection of the tumor.

Table 1 Laboratory findings.

\section{Parameters}

Potassium, $\mathrm{mmol} / \mathrm{L}$

Serum cortisol 08:00 h, $\mathrm{nmol} / \mathrm{L}$

Plasma ACTH 08:00 h, ng/L

24-h urinary free cortisol, $\mu \mathrm{g} /$ day

Cortisol 08:00 after $1 \mathrm{mg}$

overnight dexamethasone

suppression test, $\mathrm{nmol} / \mathrm{L}$

Late night salivary cortisol, $\mathrm{nmol} / \mathrm{L}$

\begin{tabular}{cccc}
\hline Results & & Reference range \\
\cline { 1 - 1 } 3.3 & & $3.5-5.1$ \\
654 & & $140-640$ \\
78.1 & & $9-52$ \\
1969 & & $36-136$ \\
302 & & $<50$ \\
& & \\
$62.4 ; 57.3$ & $<8.9$ \\
\hline
\end{tabular}

\section{Case presentation}

A 24-year-old construction worker was referred to our endocrine outpatient clinic because of suspected Cushing's syndrome. He presented with a four month's history of weight gain, obesity with predominantly central fat distribution (BMI $30 \mathrm{~kg} / \mathrm{m}^{2}$ ), moon facies, buffalo hump, peripheral edema, new onset of hypertension (blood pressure 156/99 $\mathrm{mmHg}$ ), wide purple striae on the abdomen and the inner side of the arms and thighs (Fig. 1A, B and C). He complained of disrupted sleep, fatigue, proximal muscle weakness and acne.

Medical history was, apart from atopic dermatitis, unremarkable.

\section{Investigation}

\section{Diagnosis of ACTH-dependent Cushing's syndrome}

Routine laboratory testing showed mild hypokalemia (3.3 mmol/L, normal: 3.5-5.1) and normal glucose values $(5.5 \mathrm{mmol} / \mathrm{L})$. Increased 24 -h urinary free cortisol excretion $(1969 \mu \mathrm{g} /$ day, normal <136), failed cortisol suppression following $1 \mathrm{mg}$ dexamethasone $(302 \mathrm{nmol} / \mathrm{L}$, normal $<50$ ), blunted diurnal rhythmicity of endogenous cortisol secretion (midnight salivary cortisol 62.4 and $57.3 \mathrm{nmol} / \mathrm{L}$, normal $<8.9$ ) and an ACTH concentration of $78.1 \mathrm{ng} / \mathrm{L}$ at 08:00 h (Table 1) confirmed ACTH-dependent Cushing's syndrome.

Table 2 High dose ( $8 \mathrm{mg}$ ) overnight dexamethasone suppression test (HDDST) for differential diagnosis of ACTH-dependent Cushing's syndrome.

\begin{tabular}{|c|c|c|}
\hline Parameters & Result & Interpretation \\
\hline Cortisol baseline & $655 \mathrm{nmol} / \mathrm{L}$ & \\
\hline $\begin{array}{l}\text { Cortisol at 08:00 h after } \\
\text { HDDST }\end{array}$ & $190 \mathrm{nmol} / \mathrm{L}$ & \\
\hline$\%$ Change from baseline & $71 \%$ & $\begin{array}{l}\text { Positive test for } \\
\text { Cushing's disease }\end{array}$ \\
\hline
\end{tabular}


Table 3 Bilateral inferior petrosal sinus sampling.

\begin{tabular}{|c|c|c|c|c|c|}
\hline \multirow[b]{2}{*}{ Time $(\min )$} & \multicolumn{5}{|c|}{ ACTH (ng/L) } \\
\hline & $\begin{array}{c}\text { Left } \\
\text { petrosal }\end{array}$ & $\mathrm{L} / \mathrm{P}$ & $\begin{array}{c}\text { Right } \\
\text { petrosal }\end{array}$ & $\mathrm{R} / \mathrm{P}$ & Peripheral \\
\hline-10 & 31.4 & 2.5 & 16.4 & 1.3 & 12.7 \\
\hline-5 & 85.2 & 3.6 & 31.0 & 1.3 & 23.9 \\
\hline 0 & 87.6 & 7.2 & 94.0 & 7.7 & 12.2 \\
\hline 2 & 115.0 & 1.2 & 155.0 & 1.6 & 96.3 \\
\hline 4 & 136.0 & 6.7 & 41.5 & 2.0 & 20.3 \\
\hline 6 & 134.0 & 1.2 & 141.0 & 1.3 & 110.0 \\
\hline 10 & 148.0 & 1.2 & 110.0 & 0.9 & 119.0 \\
\hline 15 & 333.0 & 2.0 & 345.0 & 2.1 & 164.0 \\
\hline
\end{tabular}

Time 0 min intravenous injection of $100 \mu \mathrm{g} C R H$. $\mathrm{ACTH}$, adrenocorticotropic hormone.

\section{Differential diagnosis of ACTH-dependent Cushing's syndrome}

High-resolution (3 Tesla) dynamic, contrast-enhanced MRI scanning showed a normal sized pituitary with no evidence for an adenoma. High dose ( $8 \mathrm{mg}$ ) overnight dexamethasone suppressed serum cortisol by $71 \%$ (Table 2). Subsequently, BIPSS revealed a positive centralto-peripheral ACTH-gradient both during the basal state (central-to-peripheral ACTH-ratio 7.7) and following stimulation with $100 \mu \mathrm{g} \mathrm{CRH}$ (ratio 6.7). The ratios of the centrally obtained samples showed no consistent lateralization pattern (Table 3). Furthermore, a pronounced increase in peripheral venous ACTH $15 \mathrm{~min}$ following CRH was observed (+900\%). Due to the compelling evidence suggesting Cushing's disease the patient was scheduled for endoscopically navigated transsphenoidal pituitary exploration.

\section{Reassessment of the diagnosis}

Only six weeks after the initial presentation rapid progression of several cushingoid features was evident and despite the recent lack of sunlight exposure the clinical exam was remarkable for a conspicuously tanned skin tone. This prompted us to consider a CRH-producing neuroendocrine tumor with subsequent secretion of ACTHprecursor molecules including $\alpha-\mathrm{MSH}$ as a differential diagnosis. A thin-cut thoraco-abdominal CT scan revealed a 5-cm tumor deriving from the cecum with infiltration of the appendix (Fig. 2A). Endoscopically obtained biopsies revealed a neuroendocrine tumor. Staging included an MRI of the abdomen and somatostatin receptor scintigraphy and showed somatostatin expression in the primary tumor but with no evidence for lymph node or liver metastases (Fig. 2B).
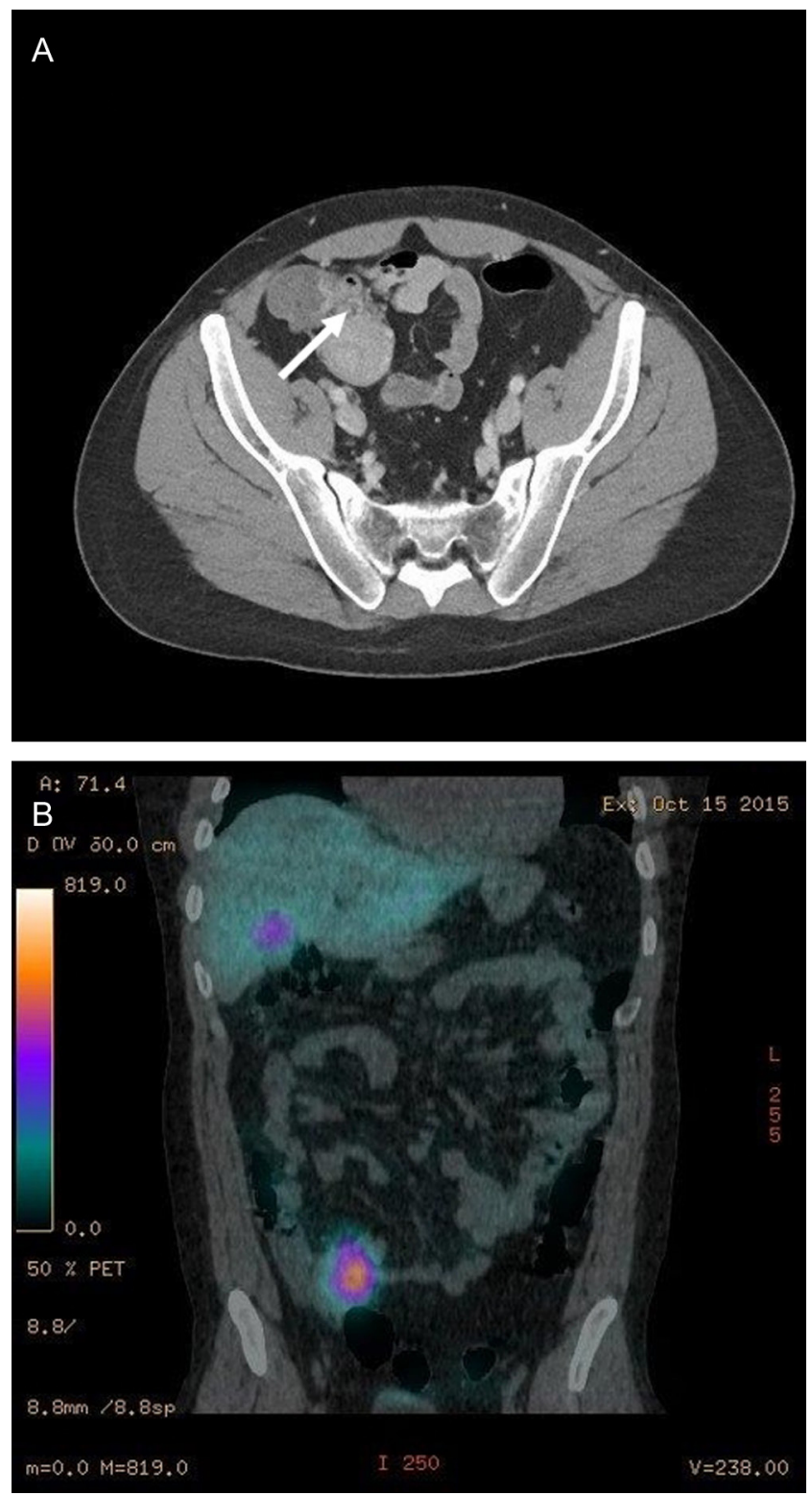

Figure 2

CT scan shows a mass in the cecum with infiltration of the appendix (arrow) (A). In-111 pentetreotide SPECT-CT with somatostatin expression in the midgut NET and gallbladder with no evidence for distant lymph node or liver metastases (B).

\section{Treatment}

\section{Medical treatment}

Due to the severe cortisol excess the patient was started on metyrapone which was gradually increased to $2000 \mathrm{mg}$ per day for two weeks before tumor resection and resulted in rapid clinical improvement and reduced serum cortisol concentrations. Perioperative thromboprophylaxis was administered. 

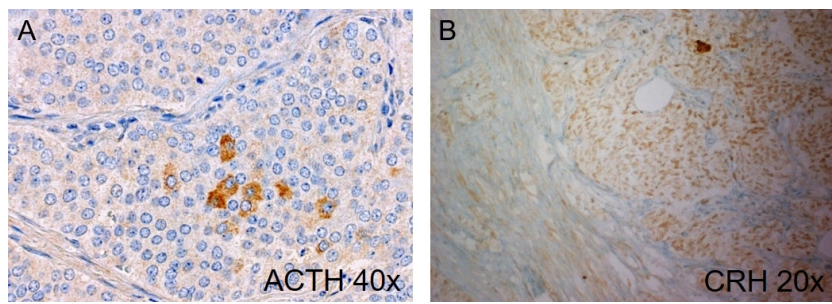

Figure 3

(A) A few cells staining positive for ACTH. (B) Impressive positive immunohistological staining for $\mathrm{CRH}$ in a cluster of tumor cells. (For immunohistochemical detection of $\mathrm{CRH}$ by DAB staining a self-made $\mathrm{CRH}$ antibody (C-13 XVII; 1:250 diluted) was used in combination with secondary goat anti-rabbit biotinylated antibody (1:300) (Vector, Burlingame, CA, USA). As the $\mathrm{CRH}$ antibody also detects mouse $\mathrm{CRH}$, mouse hypothalamus tissue was used as positive control. Negative control was performed by omitting the $\mathrm{CRH}$ antibody.)

\section{Surgical treatment}

The patient underwent right-sided hemicolectomy and concomitant cholecystectomy. Immediately after successful tumor resection serum cortisol dropped to $253 \mathrm{nmol} / \mathrm{L}$. Glucocorticoid replacement was only required for a short, two-week period.

\section{Outcome and follow-up}

\section{Histology, immunohistological staining and $\mathrm{CRH}$ analysis}

Workup of the surgical specimen demonstrated a neuroendocrine tumor of the cecum with locoregional lymph node metastases and a mitotic index (Ki-67) of $4 \%(\mathrm{G} 2)$.

Immunohistochemistry showed only a few cells positive for ACTH, but the staining for CRH was strongly positive (Fig. 3). Plasma CRH concentration measured as previously described from a baseline sample obtained during BIPSS was clearly increased (112.8 pg/mL) (16).

Thus, the final diagnosis of a predominantly CRHsecreting midgut-NET pT4, pN1 (3/14), M0, G2 leading to ectopic Cushing's syndrome was established.

\section{Follow-up}

The further course was uneventful. Signs and symptoms of Cushing's syndrome resolved within a few weeks (Fig. 1D). After a follow-up of 15 months, there is no clinical, biochemical or imaging evidence for tumor recurrence. After rapid normalization of the cortisol level, a flare of atopic dermatitis troubled the patient.

\section{Discussion}

After a diagnosis of ACTH-dependent Cushing's syndrome has been established, the a priori likelihood of Cushing's disease is close to $80 \%$. Since sellar MRI may not demonstrate a pituitary microadenoma in up to $50 \%$ of patients with Cushing's disease and the prevalence of pituitary microincidentalomas is between 10 and 40\%, a careful clinical and biochemical workup is required to identify those with an ectopic source of ACTH, prevent unnecessary pituitary exploration and provide a correct therapeutic approach to cure the cortisol excess. In a retrospective series Ilias et al. (2005) reported that 13 out of 90 patients (12.6\%) with ectopic ACTH syndrome underwent transsphenoidal pituitary surgery (17). In other case reports, transsphenoidal surgery was also falsely performed, either due to false positive biochemical tests $(6,10,11,18)$ or pituitary MRI findings (11). A rapid onset of profound weakness, severe hypokalemia, peripheral edema and hyperpigmentation due to very high cortisol and ACTH levels is highly suggestive of ectopic ACTHsecretion associated with small-cell neuroendocrine cancers but may not be observed in the majority of cases when low-grade NETs are the source of ACTH (19). Therefore, dynamic biochemical testing is key to rule out ectopic ACTH-excess. Although high-dose overnight and 48-h dexamethasone and CRH-testing are helpful, BIPSS is considered the gold standard test due to its superior sensitivity and specificity $(20,21,22)$.

Despite a relatively short history, our patient showed typical cushingoid features and the initial presentation with biochemically moderate hypercortisolism and mildly elevated plasma ACTH was well compatible with Cushing's disease. The further workup including high-dose overnight dexamethasone testing and BIPSS seemed to confirm the diagnosis. However, the persistent hyperpigmentation, which was not noticed at the initial visit since the patient was working shirtless as a construction worker and the rapid progression of symptoms during the diagnostic workup prompted us to consider an ectopic source of ACTH and/or CRH and a neuroendocrine tumor of the cecum was identified. Hyperpigmentation is a hallmark feature of ectopic Cushing's syndrome and may be observed in the majority of patients (23). Finally, increased plasma CRH concentrations and strong positive immunostaining for $\mathrm{CRH}$ with only scattered positivity for ACTH in the tumor led to the diagnosis of a predominantly 
CRH-secreting midgut NET. Since it is impossible to distinguish the source of plasma ACTH the diagnosis of a ACTH/CRH co-secreting tumor is essentially based on the immunohistochemical phenotype.

$\mathrm{CRH}$ and ACTH /CRH co-secreting tumors are extremely rare and have been described in bronchial and thymic carcinoids, islet cell carcinomas, pheochromocytomas, medullary thyroid cancers, pancreatic tumors, gastrinomas, liver tumors and smallcell lung cancers $(1,2,3,4,5,6,7,8,9,10,11,12,13$, $14,15)$. Furthermore, they have been shown to affect the results of dynamic tests and may generate false positive results during BIPSS $(5,6,8,10,12,17,24,25,26,27)$. $\mathrm{CRH}$ secretion induces diffuse hyperplasia of pituitary corticotroph cells which then oversecrete ACTH but may remain responsive to both exogenous dexamethasone and $\mathrm{CRH}$. Thus, the results of both dynamic testing with highdose dexamethasone and CRH as well as BIPSS may be misleading and mimic Cushing's disease. In agreement, the ratio of ACTH/CRH-production has been suggested to determine the response to diagnostic tests $(5,6,11)$. Since the measurement of plasma CRH is not routinely available, a high degree of clinical suspicion and careful and ongoing assessment of the patient's presentation is of paramount importance to consider ectopic ACTH/CRHproduction. A CT of the chest and abdomen should be performed if an ectopic CRH- or ACTH-producing tumor is suspected and somatostatin receptor imaging with In-111 pentetreotide and/or Ga-68 DOTATATE/DOTATOC may be a promising additional tool (28).

This case illustrates the difficulty of distinguishing between Cushing's disease and ectopic Cushing's syndrome in an exceptional ACTH/CRH co-secreting midgut neuroendocrine tumor. A careful ongoing assessment of the clinical presentation led to the diagnosis of ectopic Cushing's syndrome despite clear biochemical evidence of Cushing's disease. To the best of our knowledge this is the first case described in the literature of an ACTH/CRH co-secreting NET of the cecum mimicking Cushing's disease.

\section{Declaration of interest}

The authors declare that there is no conflict of interest that could be perceived as prejudicing the impartiality of the research reported.

\section{Funding}

This research did not receive any specific grant from any funding agency in the public, commercial or not-for-profit sector.
Patient consent

The authors confirm that they have obtained written informed consent from the patient for publication of the submitted article and accompanying images.

\section{Author contribution statement}

Dr R Streuli attended on the patient, wrote the first draft of the manuscript and did the literature search. Dr S Bilz and Dr I Krull supervised the care of the patient and contributed to the manuscript revision. Prof $\mathrm{M}$ Brändle is the head of the Division of Endocrinology and Diabetes and contributed to the clinical workup. Dr W Kolb is board-certified endocrine surgeon and performed the surgery on the patient. Dr A Enzler-Tschudy is pathologist and performed ACTH-staining of the primary tumor. Prof G Stalla is the head of Clinical Neuroendocrinology at the Max Planck Institute of Psychiatry in Munich. Immunohistological staining of $\mathrm{CRH}$ (incl. figure) and $\mathrm{CRH}$ analysis in the plasma was performed in his institute. Prof $\mathrm{M}$ Theodoropoulou did the immunohistological staining of $\mathrm{CRH}$.

\section{Acknowledgements}

The authors thank $U$ Renner and J Stalla for their contributions (organization and performance of the $\mathrm{CRH}$ analysis in the plasma).

\section{References}

1 Saeger W, Reincke M, Scholz GH \& Lüdecke DK 1993 Ectopic ACTHor CRH-secreting tumors in Cushing's syndrome. Zentralblatt Fur Pathologie 139 157-163.

2 Shahani S, Nudelman RJ, Nalini R, Kim HS \& Samson SL 2010 Ectopic corticotropin-releasing hormone $(\mathrm{CRH})$ syndrome from metastatic small cell carcinoma: a case report and review of the literature. Diagnostic Pathology 5 56. (doi:10.1186/1746-1596-5-56)

3 Sauer N, Wiesch CS zur, Flitsch J, Saeger W, Klutmann S, Zustin J, Luebke A \& Aberle J 2014 Cushing's syndrome due to a corticotropinreleasing hormone- and adrenocorticotrophic hormone-producing neuroendocrine pancreatic tumor. Endocrine Practice 20 e53-e57. (doi:10.4158/EP13001.CR)

4 Park SY, Rhee Y, Youn JC, Park YN, Lee S, Kim DM, Song SY \& Lim SK 2007 Ectopic Cushing's syndrome due to concurrent corticotropinreleasing hormone $(\mathrm{CRH})$ and adrenocorticotropic hormone (ACTH) secreted by malignant gastrinoma. Experimental and Clinical Endocrinology and Diabetes 115 13-16. (doi:10.1055/s-2007-948212)

5 Fountas A, Giotaki Z, Ligkros N, Tsakiridou ED, Tigas S, Saeger W \& Tsatsoulis A 2015 Cushing's syndrome due to CRH and ACTH co-secreting pancreatic tumor - presentation of a new case focusing on diagnostic pitfalls. Endocrine Pathology 26 239-242. (doi:10.1007/s12022-015-9384-5)

6 Schteingart DE, Lloyd RV, Akil H, Chandler WF, Ibarra-Perez G, Rosen SG \& Ogletree R 1986 Cushing's syndrome secondary to ectopic corticotropin-releasing hormone-adrenocorticotropin secretion. Journal of Clinical Endocrinology and Metabolism 63 770-775. (doi:10.1210/jcem-63-3-770)

7 Carey RM, Varma SK, Drake CR, Thorner MO, Kovacs K, Rivier J \& Vale W 1984 Ectopic secretion of corticotropin-releasing factor as a cause of Cushing's syndrome. A clinical, morphologic, and biochemical study. New England Journal of Medicine 311 13-20. (doi:10.1056/NEJM198407053110103)

8 O'Brien T, Young WF, Davila DG, Scheithauer BW, Kovacs K, Horvath E, Vale W \& Heerden JA van 1992 Cushing's syndrome associated with ectopic production of corticotrophin-releasing hormone, corticotrophin and vasopressin by a phaeochromocytoma. Clinical Endocrinology 37 460-467. (doi:10.1111/j.1365-2265.1992.tb02359.x) 
9 Oldfield EH, Doppman JL, Nieman LK, Chrousos GP, Miller DL, Katz DA, Cutler GB \& Loriaux DL 1991 Petrosal sinus sampling with and without corticotropin-releasing hormone for the differential diagnosis of Cushing's syndrome. New England Journal of Medicine 325 897-905. (doi:10.1056/NEJM199109263251301)

10 Young J, Deneux C, Grino M, Oliver C, Chanson P, \& Schaison G 1998 Pitfall of petrosal sinus sampling in a Cushing's syndrome secondary to ectopic adrenocorticotropin-corticotropin releasing hormone (ACTH-CRH) secretion. Journal of Clinical Endocrinology and Metabolism 83 305-308. (doi:10.1210/jcem.83.2.4549)

11 Karageorgiadis AS, Papadakis GZ, Biro J, Keil MF, Lyssikatos C, Quezado MM, Merino M, Schrump DS, Kebebew E, Patronas NJ, et al. 2015 Ectopic adrenocorticotropic hormone and corticotropinreleasing hormone co-secreting tumors in children and adolescents causing Cushing syndrome: a diagnostic dilemma and how to solve it. Journal of Clinical Endocrinology and Metabolism 100 141-148. (doi:10.1210/jc.2014-2945)

12 Lois K, Santhakumar A, Vaikkakara S, Mathew S, Long A, Johnson SJ, Peaston R, Neely RDG, Richardson DL, Graham J, et al. 2015 Phaeochromocytoma and ACTH-dependent Cushing's syndrome: tumor CRF-secretion can mimic pituitary Cushing's disease. Clinical Endocrinology 84 177-184. (doi:10.1111/cen.12960)

13 Asa SL, Kovacs K, Vale W, Petrusz P \& Vecsei P 1987 Immunohistologic localization of corticotrophin-releasing hormone in human tumors. American Journal of Clinical Pathology 87 327-333. (doi:10.1093/ajcp/87.3.327)

14 Schalin-Jäntti C, Asa SL, Arola J \& Sane T 2013 Recurrent acuteonset Cushing's syndrome 6 years after removal of a thymic neuroendocrine carcinoma: from ectopic ACTH to CRH. Endocrine Pathology 24 25-29. (doi:10.1007/s12022-012-9228-5)

15 Auchus RJ, Mastorakos G, Friedman TC \& Chrousos GP. Corticotropin-releasing hormone production by a small cell carcinoma in a patient with ACTH-dependent Cushing's syndrome. Journal of Endocrinological Investigation 199417 447-452. (doi:10.1007/ BF03347737)

16 Stalla GK, Stalla J, Schopohl J, WerderK von \& Müller OA 1986 Corticotropin-releasing factor in humans. I. CRF stimulation in normals and CRF radioimmunoassay. Hormone Research 24 229-245. (doi:10.1159/000180562)

17 Ilias I, Torpy DJ, Pacak K, Mullen N, Wesley RA, \& Nieman LK 2005 Cushing's syndrome due to ectopic corticotropin secretion: twenty years' experience at the National Institutes of Health. Journal of Clinical Endocrinology and Metabolism 90 4955-4962. (doi:10.1210/jc.2004-2527)

18 Salgado LR, Fragoso MCBV, Knoepfelmacher M, Machado MC, Domenice S, Pereira MAA \& Mendonça BB de 2006 Ectopic ACTH syndrome: our experience with 25 cases. European Journal of Endocrinology 155 725-733. (doi:10.1530/eje.1.02278)

19 Newell-Price J, Trainer P, Besser M \& Grossman A 1998 The diagnosis and differential diagnosis of Cushing's syndrome and pseudo-Cushing's states. Endocrine Reviews 19 647-672. (doi:10.1210/edrv.19.5.0346)

20 Arnaldi G, Angeli A, Atkinson AB, Bertagna X, Cavagnini F, Chrousos GP, Fava GA, Findling JW, Gaillard RC, Grossman AB, et al. 2003 Diagnosis and complications of Cushing's syndrome: a consensus statement. Journal of Clinical Endocrinology and Metabolism $\mathbf{8 8}$ 5593-5602. (doi:10.1210/jc.2003-030871)

21 Biller BMK, Grossman AB, Stewart PM, Melmed S, Bertagna X, Bertherat J, Buchfelder M, Colao A, Hermus AR, Hofland LJ, et al. 2008 Treatment of adrenocorticotropin-dependent Cushing's syndrome: a consensus statement. Journal of Clinical Endocrinology and Metabolism 93 2454-2462. (doi:10.1210/jc.2007-2734)

22 Newell-Price J, Bertagna X, Grossman AB \& Nieman LK 2006 Cushing's syndrome. Lancet 367 1605-1617. (doi:10.1016/S01406736(06)68699-6)

23 Beuschlein F \& Hammer GD 2002 Ectopic pro-opiomelanocortin syndrome. Endocrinology and Metabolism Clinics of North America 31 191-234. (doi:10.1016/S0889-8529(01)00025-1)

24 Malchoff CD, Orth DN, Abboud C, Carney JA, Pairolero PC \& Carey RM 1988 Ectopic ACTH syndrome caused by a bronchial carcinoid tumor responsive to dexamethasone, metyrapone, and corticotropinreleasing factor. American Journal of Medicine 84 760-764. (doi:10.1016/0002-9343(88)90116-7)

251987 Case records of the Massachusetts General Hospital. Weekly clinicopathological exercises. Case 52-1987. A 20-yearold woman with Cushing's disease and a pulmonary nodule. New England Journal of Medicine 317 1648-1658. (doi:10.1056/ NEJM198712243172608)

26 Yamamoto Y, Davis DH, Nippoldt TB, Young WF, Huston J \& Parisi JE 1995 False-positive inferior petrosal sinus sampling in the diagnosis of Cushing's disease. Journal of Neurosurgery 83 1087-1091. (doi:10.3171/ jns.1995.83.6.1087)

27 Burman P, Lethagen A, Ivancev K, Johansson L \& Sundin A 2008 Dual bronchial carcinoids and Cushing's syndrome with a paradoxical response to dexamethasone and a false positive outcome of inferior petrosal sinus sampling. European Journal of Endocrinology 159 483-488. (doi:10.1530/EJE-08-0385)

28 Isidori AM, Sbardella E, Zatelli MC, Boschetti M, Vitale G, Colao A, Pivonello R \& ABC Study Group 2015 Conventional and nuclear medicine imaging in ectopic Cushing's syndrome: a systematic review. Journal of Clinical Endocrinology and Metabolism 100 3231-3244. (doi:10.1210/JC.2015-1589)

Received in final form 26 April 2017

Accepted 31 May 2017 